\title{
The Global TANDEM-X DEM - A unique Data SET
}

\author{
Manfred Zink ${ }^{1}$, Alberto Moreira ${ }^{1}$, Markus Bachmann ${ }^{1}$, Paola Rizzoli ${ }^{1}$, \\ Thomas Fritz ${ }^{2}$, Irena Hajnsek ${ }^{1,3}$, Gerhard Krieger ${ }^{1}$, Birgit Wessel ${ }^{4}$ \\ ${ }^{1}$ German Aerospace Center (DLR), Microwaves and Radar Institute \\ ${ }^{2}$ German Aerospace Center (DLR), Remote Sensing Technology Institute \\ ${ }^{3}$ ETH Zürich, Chair of Earth Observation and Remote Sensing, Switzerland \\ ${ }^{4}$ German Aerospace Center (DLR), German Remote Sensing Data Center \\ Oberpfaffenhofen, Germany, E-Mail: manfred.zink@dlr.de
}

\begin{abstract}
TanDEM-X (TerraSAR-X add-on for Digital Elevation Measurements) is an Earth observation radar mission that consists of a SAR interferometer built by two almost identical satellites flying in close formation [1]-[4]. With a typical separation between the satellites of 120 to $500 \mathrm{~m}$ a global Digital Elevation Model (DEM) with $2 \mathrm{~m}$ relative height accuracy at $12 \mathrm{~m}$ posting has been generated. While the main mission phase for DEM data acquisition has been finished in 2014, the processing of the global TanDEM-X DEM was concluded in September 2016. Final DEMs are well within specifications and feature an extremely low percentage of void areas. Following the DEM data acquisition the capabilities of this unique mission for new scientific application have been demonstrated. Satellite resources allow for a continuation of the joint TerraSAR$\mathrm{X} /$ TanDEM-X mission for several years. Beyond improvements of the global DEM the mission will be dedicated to the generation of a global 3D information change layer and of the corresponding DEM updates as a demonstration of the future climate research and environmental monitoring mission Tandem-L.
\end{abstract}

Index Terms - TanDEM-X, bistatic SAR formation, SAR interferometry, global Digital Elevation Model (DEM), DEM updates

\section{MISSION OBJECTIVES}

The primary objective of the TanDEM-X mission is the generation of a global Digital Elevation Model (DEM) of the Earth's surface with unprecedented accuracy (see Table 1) as the basis for a wide range of commercial applications as well as for scientific research [1].

It is expected that this data set will become a new reference in geosciences and remote sensing applications since its 3-D information content is ca. 30 times more accurate than presently available global scale DEM data sets.

Beyond the generation of the global DEM as the primary mission goal, TanDEM-X supports applications based on Along-Track Interferometry (ATI) and the demonstration and application of new SAR techniques, with focus on multistatic SAR, polarimetric SAR interferometry, digital beam forming and super resolution.

\begin{tabular}{|c|c|c|}
\hline Parameter & Specification & Requirement \\
\hline $\begin{array}{c}\text { Absolute Height } \\
\text { Accuracy }\end{array}$ & $\begin{array}{l}90 \% \text { linear error } \\
\text { (globally) }\end{array}$ & $\leq 10$ meters \\
\hline \multirow{2}{*}{$\begin{array}{c}\text { Relative Height } \\
\text { Accuracy }\end{array}$} & \multirow{2}{*}{$\begin{array}{l}90 \% \text { linear point-to- } \\
\text { point error } \\
\text { (in } 1^{\circ} \times 1^{\circ} \text { geocell) }\end{array}$} & $\begin{array}{c}\leq 2 \text { meters } \\
\text { (slope } \leq 20 \%)\end{array}$ \\
\hline & & $\begin{array}{c}\leq 4 \text { meters } \\
(\text { slope }>20 \%)\end{array}$ \\
\hline
\end{tabular}

Table 1. Global DEM Height Accuracy Requirements [5].

\section{MISSION STATUS}

After the launch in June 2010 and the subsequent commissioning phase, global DEM acquisitions started in December 2010. Parallel to the first month of operational data acquisition the team concentrated its efforts on the calibration of the bistatic interferometer. Correction of differential delays between TSX and TDX was necessary to facilitate the utilization of radargrammetry for resolving the $2 \pi$-ambiguity band. Phase, delay and baseline calibration have reached such an accuracy level [6], that more than $90 \%$ of all so-called Raw DEMs (long data takes are processed to scene based DEMs of $50 \mathrm{~km}$ by $30 \mathrm{~km}$ extension) are within $\pm 10 \mathrm{~m}$ of DEMs derived from SRTM/ICESat data already before the final calibration step using ICESat data as reference heights. More than 500,000 Raw DEMs have been 


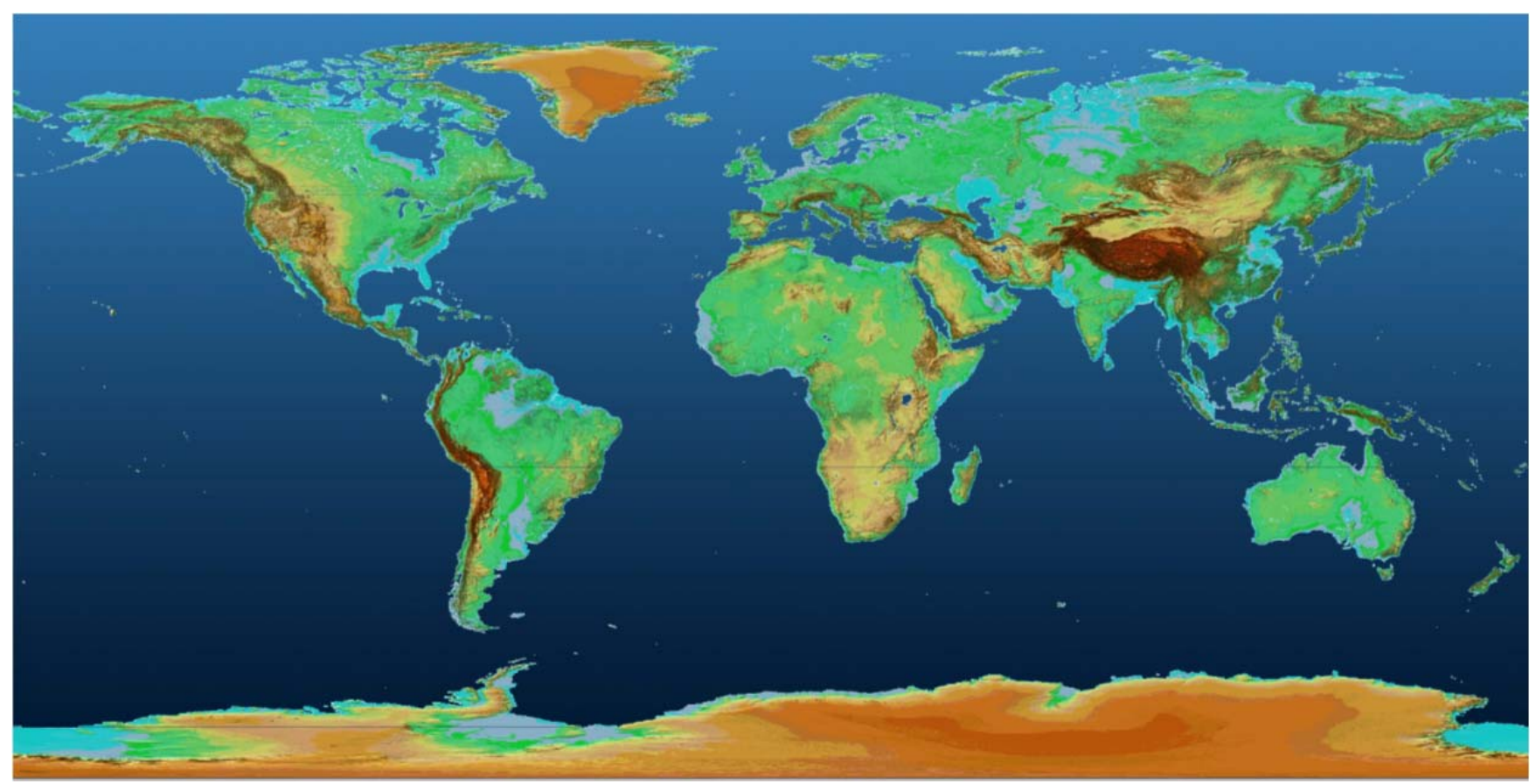

Fig. 1. The global TanDEM-X DEM is a consistent data set covering all land surfaces at unprecedented absolute height accuracy of about $1 \mathrm{~m}$ at a horizontal sampling of $12 \mathrm{~m}$ by $12 \mathrm{~m}$. Between 2011 and 2014 at least two acquisitions have been collected by the bistatic TanDEM-X SAR interferometer, mountainous areas have covered up to six times.

generated in a fully automated process employing multibaseline interferometric techniques [7].

The first and second global coverages (except Antarctica) were completed in January 2012 and March 2013, respectively. After some gap-filling, Antarctica was mapped for the first time under local winter conditions. In early August 2013 the satellite helix formation was changed to allow imaging of mountainous areas from the opposite viewing geometry [8]. Due to a low SNR, desert areas had to be re-acquired as well, but at steeper incidence angles. Afterwards the satellites were maneuvered back to the original formation and Antarctica was covered again at larger baselines. The primary data acquisition program was concluded mid-2014.

A comprehensive system has been established for continuous performance monitoring and verification [9], [10], [11] including feedback to the TanDEM-X acquisition planning for additional acquisitions. Since the end of 2013 the final calibration and mosaicking chain has been fully operational and completed the global DEM consisting of more than $19,0001^{\circ}$ by $1^{\circ}$ (lat/long) tiles in September 2016 [12].

\section{GLOBAL DEM PERFORMANCE}

The quality of the final DEMs is well within the expected performance for the global DEM. Fig. 2 shows as an example the absolute height accuracy $(90 \%$ linear error) per tile derived from the comparison of the TanDEM-X heights against ICESat validation points. The cumulated absolute height error over the complete data set totals $3.5 \mathrm{~m}$. If the forested and ice-covered areas are excluded, where the $\mathrm{X}$-band reflective surface deviates from the laser surface due to different penetration, we end up with an outstanding 0.9 $\mathrm{m}$ global absolute height error that is one order of magnitude below the 10-meter requirement.

As the system is very well calibrated and tilts and trends are negligible, the relative height accuracy is well described solely by the random errors in the system. It can be calculated from the interferometric coherence and the resulting phase error. It is specified as the point-to-point error within a $1^{\circ}$ by $1^{\circ}$ tile. Again, excluding ice and forest areas, where additional volume decorrelation deteriorates the coherence and in consequence the relative height error, $97.8 \%$ of all DEM tiles fulfil the relative height error specification of $2 \mathrm{~m}(4 \mathrm{~m})$ for flat (steep) terrain.

Finally, compared to SRTM the TanDEM-X DEM features a much lower percentage of void areas (global count of $0.1 \%$ ), especially in desert areas, a result of the reacquisition at steeper incidence angles and hence better SNR. Further details on the TanDEM-X DEM quality can be found in [13].

The above mentioned performance monitoring used the interferometric coherence as the key quantity to control the data acquisition, processing and mosaicking. In case of volume scatterers the coherence is mainly determined by the volume decorrelation effect, which in turn can be used 


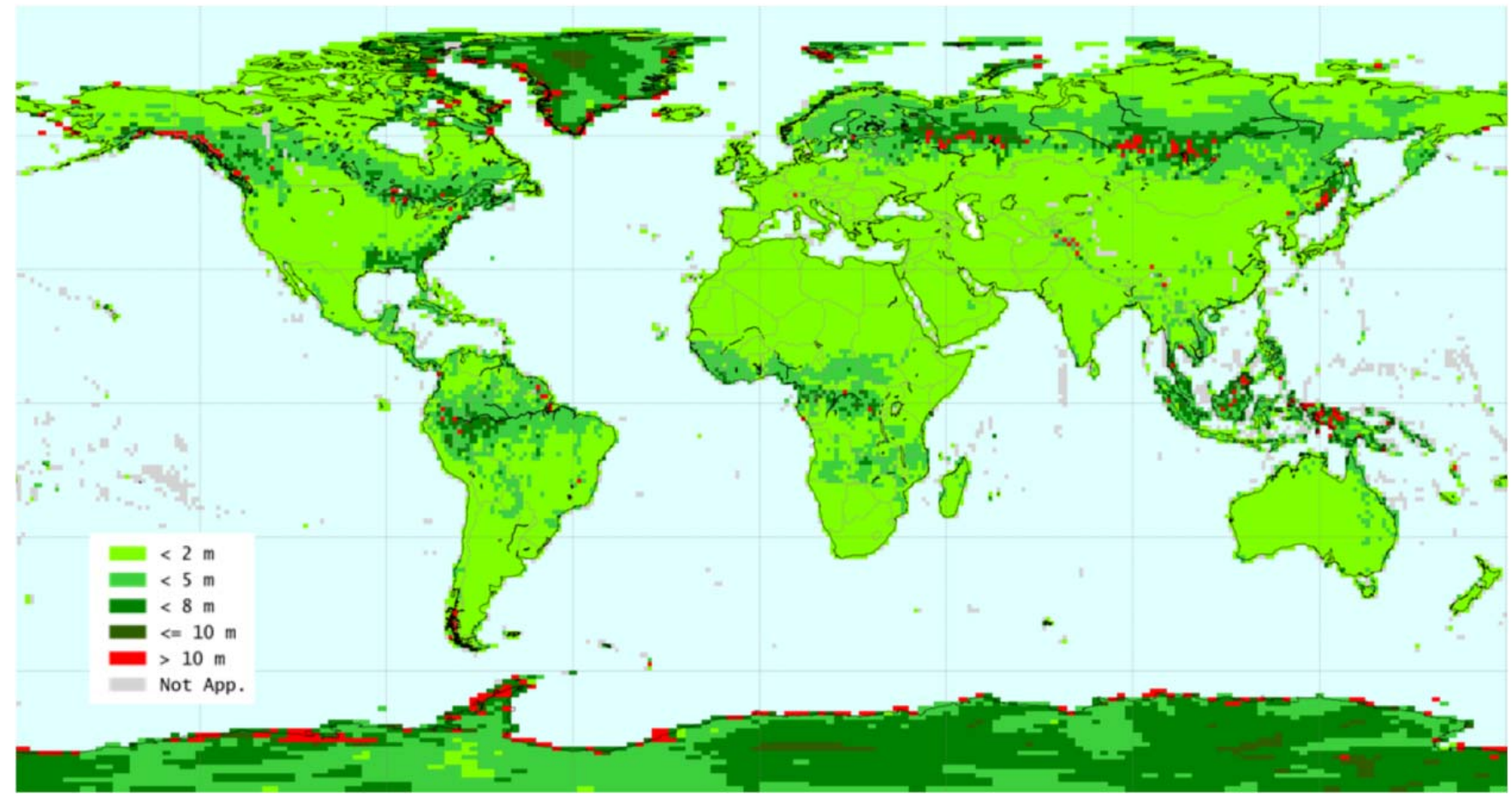

Fig. 2. TanDEM-X DEM absolute height accuracy ( $90 \%$ linear error) per $1^{\circ}$ by $1^{\circ} \mathrm{DEM}$ tile; the cumulated absolute height error for ice-free and non-forested areas is with $0.9 \mathrm{~m}$ one order of magnitude below the 10 -m requirement.

discriminate forested and non-forested areas as shown in Fig. 3. As a byproduct of the global DEM a global forest map [14] at a resolution of $50 \mathrm{~m} \times 50 \mathrm{~m}$ is currently being generated and is planned to be made freely available for scientific users.

As both satellites are still working very well and have plenty of resources left, an agreement to continue the mission was concluded between DLR und AIRBUS Defence \& Space. Key objectives for this extra mission phase are the acquisition of interferometric data for improvements of the global DEM and the generation of a global change layer, that can be considered as a demonstration for the future climate research and environmental monitoring mission Tandem-L. If the baseline geometries are suitable, further scientific experiments will be included in the timeline as well.

\section{CONCLUSION}

The TanDEM-X mission opens a new era in spaceborne radar remote sensing. A large single-pass SAR interferometer with adjustable baselines has been formed by adding a second, almost identical radar satellite to TerraSAR-X and flying both satellites in a closely controlled formation.

The generation of the global DEM, the primary mission objective, has been successfully completed. Quality and coverage of the data are outstanding. A science phase dedicated to demonstrating applications based on alongtrack interferometry and new SAR techniques has been finished last year. A summary of the most interesting results can be found in [15]. Continuation of the mission was approved with the main objective to use bistatic interferometry in close formation flight to generate a global $3 \mathrm{D}$ information change layer.

TanDEM-X has demonstrated the feasibility of an interferometric radar mission with close formation flight and delivers an important contribution for the conception and design of future SAR missions. One example is Tandem-L, a mission for monitoring dynamic processes on the Earth surface with unprecedented accuracy [16].

\section{REFERENCES}

[1] Krieger, G., Moreira, A., Fiedler, H., Hajnsek, I., Werner, M., Younis, M., Zink, M.: TanDEM-X: A Satellite Formation for High Resolution SAR Interferometry. IEEE Transactions on Geoscience and Remote Sensing, Vol. 45, No. 11, pp. 3317-3341, Nov. 2007.

[2] Zink, M., Bachmann, M., Bräutigam, B., Fritz, T., Hajnsek, I., Krieger, G., Moreira, A., Wessel, B.: TanDEM-X: The New Global DEM Takes Shape. IEEE Geoscience and Remote Sensing Magazine, Vol. 2, No. 2, June 2014.

[3] Krieger, G. et al.: TanDEM-X. In: Distributed Space Missions for Earth System Monitoring, Chapter 13, Springer 2012, pp. $387-435$. 
[4] Krieger, G., Hajnsek, I., Papathanassiou, K., Younis, M., Moreira, A.: Interferometric Synthetic Aperture Radar (SAR) Missions Employing Formation Flying. Proceedings of the IEEE, Vol. 98, No. 5, 2010.

[5] B. Wessel, "TanDEM-X Ground Segment - DEM Products Specification Document", Public Document TD-GS-PS-0021, Issue 3.1, 2016.

[6] J. Hueso González, J. Walter Antony, M. Bachmann, G. Krieger, M. Zink, D. Schrank, M. Schwerdt, "Bistatic System and Baseline Calibration in TanDEM-X to Ensure the Global Digital Elevation Model Quality”, ISPRS Journal of Photogrammetry and Remote Sensing, Vol. 73, pp. 3-11, 2012.

[7] T. Fritz, H. Breit, C. Rossi, U. Balss, M. Lachaise, U. Duque, "Interferometric Processing and Products of the TanDEM-X Mission”, International Geoscience and Remote Sensing Symposium (IGARSS), Munich, Germany, 2012.

[8] D. Borla Tridon, et.al., "TanDEM-X: DEM Acquisition in the Third Year Era", Int. Journal of Space Science and Engineering, Vol. 1, No.4 pp. $367-381,2013$.

[9] M. Martone, B. Bräutigam, P. Rizzoli, C. Gonzalez, M. Bachmann, G. Krieger, "Coherence Evaluation of TanDEM-X Interferometric Data," ISPRS Journal of Photogrammetry and Remote Sensing, Vol. 73, pp. 21-29, 2012.

[10] P. Rizzoli, B. Bräutigam, T. Kraus, M. Martone, G. Krieger, "Relative Height Error Analysis of TanDEM-X Elevation Data,"
ISPRS Journal of Photogrammetry and Remote Sensing, Vol. 73, pp. 30-38, 2012.

[11] B. Bräutigam, P. Rizzoli, M. Martone, M. Bachmann, T. Kraus, G. Krieger, "InSAR and DEM Quality Monitoring of TanDEM-X,“ International Geoscience and Remote Sensing Symposium (IGARSS), Munich, Germany, 2012.

[12] B. Wessel, et.al., "Design of the DEM Mosaicking and Calibration Processor for TanDEM-X", European Conference on Synthetic Aperture Radar (EUSAR), Friedrichshafen, Germany, 2008.

[13] C. Wecklich, et.al., "TanDEM-X Height Performance and Data Coverage", International Geoscience and Remote Sensing Symposium (IGARSS), Fort Worth, Texas, USA, 2017.

[14] C. Wecklich, et.al., "Production of a Global Forest/NonForest Map Utilizing TanDEM-X Interferometric SAR Data", International Geoscience and Remote Sensing Symposium (IGARSS), Fort Worth, Texas, USA, 2017.

[15] I. Hajnsek, et.al., "TanDEM-X Science Activities", International Geoscience and Remote Sensing Symposium (IGARSS), Fort Worth, Texas, USA, 2017.

[16] A. Moreira, et.al., "Tandem-L: A Highly Innovative Bistatic SAR Mission for Global Observation of Dynamic Processes on the Earth's Surface", IEEE Geoscience and Remote Sensing Magazine, Vol. 3, No. 2, June 2015.

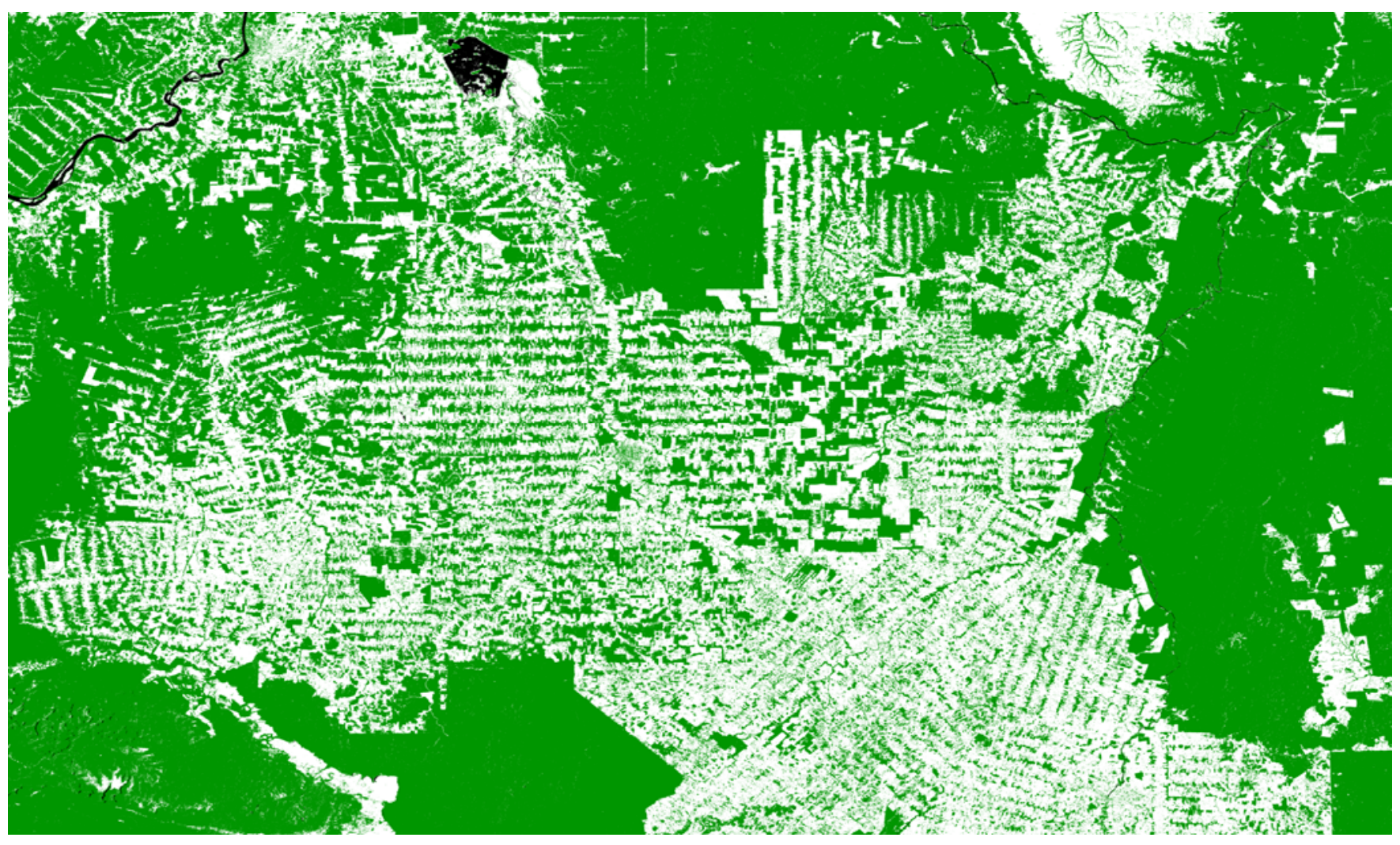

Fig. 3. Forest map of an area in Rondonia/Brazil derived from TanDEM-X coherence quick looks (50 m x $50 \mathrm{~m}$ resolution). 